\title{
APRESENTANDO O DOSSIÊ: ESTUDOS SOBRE AS SOCIEDADES JÊ (KAINGANG E XOKLENG) NO SUL DO BRASIL EM PERSPECTIVA
}

\author{
Flavio Braune Wiik ${ }^{1}$ \\ Lúcio Tadeu Mota ${ }^{2}$
}

\begin{abstract}
presente dossiê teve por objetivo reunir estudos e pesquisas contemporâneos conduzidos entre os povos indígenas Kaingang e Xokleng, também nominados pela antropologia de Jê do Sul do Brasil, ou Jê Meridionais.
\end{abstract}

Conforme o Censo de 2010 do IBGE, os Kaingang eram 37.470 pessoas e os Xokleng somavam 1.820. Ambas as populações estão distribuídas em 72 Terras Indígenas, localizadas desde o oeste do estado de São Paulo, passando pelo planalto meridional nos estados do Paraná, Santa Catarina e Rio Grande do Sul até a periferia de Porto Alegre. Tanto os Kaingang quanto os Xokleng têm mantido taxas de crescimento demográfico superior às da população não indígena e firmado seus protagonismos em diversos campos de atuação.

Nas últimas três décadas houve no Brasil um crescimento das pesquisas relacionadas às populações indígenas. Esse interesse engloba os diversos campos de investigação, e posiciona essas populações enquanto protagonistas de suas histórias e das relações socioculturais que mantém com as populações do entorno

\footnotetext{
${ }^{1}$ Professor de Antropologia e Etnologia junto ao Departamento e Programa de Pós-graduação de Ciências Sociais da Universidade Estadual de Londrina (UEL). flaviowiik@gmail.com

${ }^{2}$ Professor de História na Universidade Estadual de Maringá (UEM), e nos Programas de PósGraduação e História da UEM e da UFGD, e pesquisador no Laboratório de Arqueologia, Etnologia e Etno-História da UEM. Itadeumota@gmail.com
} 
e não apenas como vítimas da inexorabilidade histórica de ocupação de seus territórios pelas frentes de ocupação.

0 interesse pela temática foi impulsionado pela promulgação da Constituição Federal em 1988, que garantiu direitos aos povos indígenas, principalmente aqueles relativos à terra, o que gerou novas demandas para estudos dessas populações, configurando um processo similar ao que tinha ocorrido nos Estados Unidos no final da Segunda Guerra Mundial, com a promulgação (em 1946) do Indian Claim Act (ICA). O ICA permitiu que os indígenas reivindicassem compensações pelas terras perdidas, gerando demandas por pesquisas em diversas áreas das humanidades, o que fez com que muitos profissionais (historiadores, antropólogos, arqueólogos, linguistas etc) se envolvessem na produção de estudos e laudos que subsidiassem as demandas dos povos indígenas, propiciando assim uma mudança nas perspectivas dos estudos das populações indígenas.

Em diversas partes do Brasil, na primeira metade da década de 80 do século XX, o assunto "direitos das populações indígenas" foi tema de muitas reuniões, encontros e seminários. Destacamos duas reuniões organizadas pelo professor Silvio Coelho dos Santos em Santa Catarina: a primeira, ocorrida em outubro de 1980 e outra em setembro de 1983. Nelas estiveram reunidos antropólogos, advogados, juristas, representantes da Ordem dos Advogados do Brasil (OAB) e da Fundação Nacional dos Índios (Funai). David Maybury-Lewis, um renomado pesquisador no campo da Antropologia social, assinalou que uma das conclusões mais importante da primeira reunião "foi a de que é chegada a hora do Brasil enfrentar o fato de ser uma sociedade multi-étnica e de agir de acordo com este fato" (MAYBURY-LEWIS, 1982, p. 12). Já Silvio Coelho dos Santos sintetizou, no documento conclusivo da segunda reunião, que "o pluralismo cultural" deveria se "constituir o fundamento de uma nova política indigenista centrada no exercício e respeito à diferença e à autonomia." (SANTOS, 1985, p. 12).

No ano seguinte, em 1983, Manuela Carneiro da Cunha organizou um Grupo de Trabalho (GT) na Associação Nacional de Pós-Graduação em Ciências Sociais (ANPOCS) e na Associação Brasileira de Antropologia (ABA) para discutir as temáticas relacionadas à história indígena e ao indigenismo. Participaram desse GT diversos historiadores, arqueólogos e antropólogos. Cunha publicou parte dessa produção na Revista de Antropologia, periódico do Departamento de Antropologia Social da Universidade de São Paulo. Na introdução que fez aos números 30, 31 e 32 da revista, dedicados especialmente à temática indígena, ela 
escreveu que a história dos povos indígenas no Brasil estava mudando porque as "reticências", metodológicas dos historiadores e teóricas dos antropólogos, cediam lugar para novas formas de abordagens e legitimação de novas fontes nas reflexões sobre a história indígena (CUNHA, 1991, p. 1-3).

Nos Estados Unidos o interesse por estudar os processos históricos e socioculturais das populações indígenas, trouxeram consigo questões e problemas relacionados ao uso de fontes, definições de conceitos e questões relacionadas às metodologias a serem utilizadas. Essas discussões, que se prolongaram por toda a década de 1950 no seio da Sociedade Americana de Etno-História, foram sistematicamente publicadas em diversas revistas de Antropologia e História dos EUA e Canadá e principalmente na Ethnohistory (MOTA, 2014). 0 debate ocorrido nos EUA contribuiu para o uso de fontes, tais como: tradições orais, etnoconhecimentos, elementos da cultura material, dados linguísticos, dados etnográficos e evidências documentais para estudar as transformações nas sociedades nativas da América.

As contribuições da Etno-História americana dos anos de 1950/60, os debates ocorridos no Brasil na década de 1980 e o protagonismo indígena atual inspiraram a realização deste dossiê, que tem como intuito reunir reflexões sobre a temática indígena que destacassem a importância da conjugação de dados e métodos de várias disciplinas como: Arqueologia, História, Antropologia, Linguística, Geografia, Ecologia e Educação como perspectivas para abordagem dos processos de transformação/manutenção das sociedades Jê do Sul do Brasil, principalmente no que diz respeito à valorização das tradições orais, da cultura material, dos dados linguísticos e dos etno-conhecimentos desses povos.

0 dossiê é protagonizado pelo artigo de Kimiye Tommasino e Ledson Kurtz de Almeida, intitulado "Territórios e Territorialidades Kaingang: a reinvenção dos espaços e das formas de sobrevivência após a conquista". Nele, os autores argumentam que a invasão e a ocupação dos territórios tradicionais Kaingang por representantes da sociedade nacional culminou na introdução dos modos de uso mercantil e privado característicos da sociedade nacional. Com isso, deflagrou-se, entre os Kaingang, processos de cisão temporal e uma consequente conceitualização dual em "um novo tempo (uri) em oposição ao tempo antigo (vãsy)". 0 tempo uri, pós-invasão pelos fóg ("Brancos"), é caracterizado pelo confinamento, pela busca de novas formas de sobrevivência em territórios drasticamente reduzidos e pela dilapidação dos recursos naturais neles existentes, o que se antepõe idealmente ao tempo vãsy, i.e.; ao período pré-contato, tido pelos indígenas como o da abundância e da harmonia. Seguindo Marshall Sahlins, 
os autores afirmam que "o novo tempo Kaingang (o uri) contém o tempo antigo (o vãsy) [podendo-se ver neste] uma atualização histórica daquele [...]”, onde ordens culturais determinam modos próprios de produção histórica. Sob esta égide, sustentam os autores, os Kaingang mantiveram sentidos e movimentos de territorialização próprios e sobrepostos às territorialidades impostas pelo Estado e seu ethos dominante (como, por exemplo, 0 ato de significar como seus os atuais espaços urbanos que se sobrepõem aos seus territórios tradicionais, tidos como extensão que ultrapassam os das terras indígenas delimitadas pelo fóg). Entretanto, afirmam os autores, esse processo se dá em um novo contexto histórico marcado por vários conflitos.

Cabe ainda, e sobretudo, ressaltar que o artigo de Tommasino e Kurtz de Almeida, aparece também traduzido na língua inglesa. 0 intuito é o de difundir internacionalmente a contribuição dos autores para os estudos dos Jê Meridionais, assim como tornar público à comunidade antropológica internacional (não leitora da língua portuguesa) o nosso reconhecimento e tributo à importante obra da Professora Kimiye Tommasino sobre os Kaingang e demais Índios no sul do Brasil nas últimas décadas.

A este, segue 0 artigo de Almir de Souza "A invasão das terras Kaingang nos Campos de Palmas. 0 processo contra a liderança indígena Vitorino Condá (183944)”, que traz uma contribuição para a História Indígena. Em particular, este artigo apresenta uma análise documental sobre o processo judicial movido contra o cacique Vitorino Condá e a invasão de territórios tradicionais Kaingang no Planalto Meridional a cargo de autoridades públicas e fazendeiros no Brasil Império. Estas ações refletiam a nova visão político-econômica sobre usos do território implementadas no período, a qual visava, entre outras frentes, abrir espaço para a colonização e a criação de novos povoados e vilas. A expulsão dos Kaingang deve ser vista como um episódio da história de contato dos índios com representantes dos modos e ideologias luso-brasileiras. Como o artigo bem mostra, a ofensiva contra os Kaingang gerou conflitos e confrontos, que demonstram o protagonismo indígena traduzido em ações de resistência, bem como em estratégias políticas lideradas por Condá.

Em "Garra de jaguar, botão de camisa, cartucho de bala: um olhar sobre arte, poder, prestígio e xamanismo na cultura material Kaingang", Ana Elisa Freitas (re)acessa categorias espaço-temporais duais incrustadas na cosmografia Kaingang, entrecruzando-as com a sua cultura material e seus produtores ao longo da história. Vis-à-vis com novas perspectivas teóricas e questões que permeiam a Etnologia contemporânea, a autora propõe uma análise sobre a 
relação existente entre objetos, arte/estética, territorialidade, contato interétnico, etnohistória, etnoecologia e ressignificações históricas Kaingang no sul do Brasil. Ou seja, argumenta que manifestações estéticas e produção de objetos pelos Kaingang ao longo do tempo (em especial na região de presença tradicional indígena que fora sobreposta pela cidade de Porto Alegre, de onde parte o centro de sua pesquisa etnográfica) adquirem significado mister para a significação do Uri/presente e do Waxi/passado Kaingang, segundo regimes de alteridade, perspectivas, exercício e reconhecimento de poderes e conhecimentos existentes entre os xamãs que "transitam" entre estas dimensões espaço-temporais. Segundo Freitas, seu "[...] estudo buscou compreender que elementos materiais e simbólicos são importantes para a configuração do pertencimento Kaingang a estes espaços [e tempos] [...] para convertê-los efetivamente em parte de seu território".

0 artigo "Os Kujà são diferentes? Doenças invisíveis, aliança e guerra no xamanismo Kaingang", escrito por Rogério Gonçalves da Rosa, apresenta uma contribuição singular para os estudos do xamanismo no campo da Etnologia. A partir de pesquisas etnográficas realizadas nas Terras Indígenas Xapecó, Votouro e Nonoai, Rosa considera 0 fenômeno da rivalidade entre os próprios $k u j a ̀$ curandores. Mais especificamente, infere de maneira detalhada sobre as concepções nativas de diferenciação elencadas pelos seus interlocutores. Para tal, considera as idiossincrasias, as alianças e as rivalidades nas falas e casos concretos narrados pelos kujà/curandores. Estes, por sua vez, ganham textura e significância quando antepostos e contextualizados à luz de aspectos inerentes à cosmologia, ao xamanismo, ao universo etnomédico e ao espaço destinado às alianças e rivalidades no universo, assim como às dinâmicas socioculturais Kaingang. A título de exemplo, Rosa apresenta aspectos que sustentam tanto as alianças, quanto as rivalidades entre os kujà tais como: o compartilhamento ou não de jagrẽ (espíritos auxiliares) comuns, as especificidades das doenças invisíveis e a própria competição entre kujà e demais xamãs na oferta da cura. Ao final, e de maneira clássica, a análise de Rogério da Rosa nos conduz a constatação de que as idiossincrasias e particularidades dos poderes e forças manipuladas pelos kujà amalgamam-se em um ethos comum ao universo cosmográfico Kaingang, fato que nos possibilita identificar elementos que dão unidade à experiência e ao exercício do xamanismo entre eles.

Ana Caroline Goulart apresenta o artigo intitulado "Reciprocidade, moralidades e o ethos guerreiro no Uri: práticas Kaingang na Universidade Estadual de Londrina”. A autora também recorre à categoria espaço-temporal 
Kaingang uri para argumentar sobre os processos de ressignificação e apropriações indígenas acerca e em resposta à política paranaense de formação superior indígena iniciada em 2002. De acordo com a pesquisa etnográfica realizada por Goulart, as relações - e seus sentidos - estabelecidas entre alunos e lideranças Kaingang e demais agentes (atrelados ao cumprimento desta política junto à Universidade Estadual de Londrina) são mediadas por regimes de alteridade peculiares. Tais regimes respondem, são ontologicamente caracterizados e geram uma série de conflitos e tensões. Estes últimos replicam uma economia de trocas e barganhas, por parte dos Kaingang, que, ao final, respondem por meio da constituição de identidades construídas e reorganizadas no espaço da universidade a partir da agência Kaingang no tempo presente. Este presente, aliás, é o tempo no qual eles este circulam e vivenciam embates, ao mesmo passo em que cautelosamente interagem com os fóg ("Brancos"), de forma a atualizarem, em novas paisagens forjadas, os mesmos territórios e ocupação desde os tempos imemoriais. Por fim, o ensaio de Ana Goulart nos remete à dinâmica inerente à vida social e ao fenômeno da cultura, ou seja, a matérias ontologicamente marcadas por rupturas e continuidades segundo as variáveis de tempo e espaço.

0 artigo "Os circuitos de trabalho indígena: possibilidades e desafios para acadêmicos e profissionais Kaingang na gestão das políticas públicas", escrito por Wagner do Amaral, Michelle Rodrigues e Jenifer Bilar, dialoga intimamente com 0 texto de Goulart, na medida em que faz um balanço crítico acerca dos impactos existentes na formação, na atuação e nas perspectivas de inserção profissionais Kaingang formados pelas universidades públicas do Paraná. Os autores apresentam o resultado de pesquisas realizadas sobre as trajetórias desses acadêmicos egressos, refletindo sobre a inserção profissional e os novos circuitos de trabalho voltados para a gestão dos programas e políticas socioeconômicas dirigidas às populações indígenas, fato que leva os Kaingang com diploma superior a um "duplo pertencimento": como sujeitos e objetos das novas políticas de formação superior, profissionalização, atuação profissional nos postos de trabalho disponibilizados pelas políticas socioeconômicas "na ponta" (ou seja, existentes nas Terras Indígenas que idealmente devem e/ou desejam atuar). Como resultado, o "duplo pertencimento" desses sujeitos faz com esses novos profissionais atuem em campos contraditórios, caracterizados por lógicas e estruturas descontínuas, que medeiam a estrutura do Estado e a cultura Kaingang.

$\mathrm{Na}$ sequencia, Lucas Cimbaluk apresenta um recente estudo etnográfico realizado entre os Kaingang da Terra Indígena Apucaraninha (PR). 0 artigo "Respeito e reciprocidade, referenciais da moralidade Kaingang" argumenta que 0 
conceito de moralidade deve ser concebido como base analítica das sociabilidades Kaingang, na medida em que ela expressa a noção de respeito balizada nas interações cotidianas, fundamentando até mesmo a reciprocidade Kaingang Segundo o autor, as especificidades do conteúdo moral entre os Kaingang articulam-se com a noção do dever do exercício da generosidade entre as famílias. Ademais, a moral se faz presente através de categorias êmicas, tais como "lei" vivida e expressa pela liderança, que exerce 0 seu poder (moral) rogando para que a "bagunça" seja evitada, assim como apontando os "erros" cometidos. Através da argumentação proposta por Cimbaluk, infere-se que o poder atribuído à liderança (aos caciques) é mediado pela moralidade e seus conteúdos específicos, tornandose referenciais concretos para a própria constituição da coletividade. Neste sentido, a moralidade estende-se e se faz presente no tempo e no espaço, dando forma e qualificando as interações sociais, a morfologia, a construção da pessoa e 0 parentesco Kaingang. Finalmente, por oposição e contraste, a moralidade também é balizadora dos regimes de diferenciações e oposições, ou seja, dos regimes de alteridade.

No último artigo que compõe este dossiê, cujo título é "Mulheres e crianças Kaingang da aldeia Icatu/SP: etiquetas de convivialidade”, Thais Mantovanelli critica a visão distorcida que se tem sobre os Kaingang em São Paulo, que os qualifica como "aculturados" ou "assimilados", a partir de uma etnografia sobre regras de etiqueta singulares que medeiam as relações de convivência entre mulheres e crianças Kaingang na Terra Indígena Icatu. Em seu texto, a autora discorre sobre as especificidades das relações estabelecidas entre mulheres e crianças e entre os espaços doméstico e público. Em diálogo com a Antropologia da criança, Montovanelli observa que as crianças da aldeia Icatu têm permissão somente para circular em espaços reduzidos da aldeia, restrito aos espaços das casas de suas mães, tias e avós maternas. Isso faz com que, entre os Kaingang de Icatu, as crianças sigam uma lógica da não visitação entre pessoas de casas distintas - o que está, inclusive, em oposição a outras realidades etnográficas constatada em diversas etnias. Portanto, afirma a autora, a imagem atribuída à criança indígena como "mensageira ou livre de restrições a certos convívios" não se aplica neste caso. Ademais, a etiqueta preza pela não circulação de pessoas nas casas segundo distinções e classes de gênero e de idade. Ainda no que diz respeito a este texto, Mantovanelli discorre sobre as maneiras preferenciais de convívio entre os índios Kaingang e Terena que coabitam a Terra Indígena etnografada, complementando a análise realizada no artigo anterior, de Cimbaluk, uma vez que, para os dois autores a contribuição reside na análise das regras específicas de 
convivialidade, mediadas por princípios morais e de constituição da pessoa entre os Kaingang, é central.

Cabe-nos, finalmente, agradecermos a cada um/a dos/as autores/as que colaboraram com os artigos para dossiê proposto. Os oito artigos submetidos são, sem sombra de dúvida, exemplos concretos do encontro de gerações de pesquisadores, bem como de temas, que se entrecruzam, inovam e enriquecem 0 campo da Etnologia, sobretudo no que se refere aos estudos acerca das populações Jê meridionais.

\section{REFERÊNCIAS}

CUNHA, Manuela Carneiro da. Introdução ao volume especial da Revista de Antropologia sobre História Indígena. Revista de Antropologia, São Paulo, v. 3032, p. 1-8, 1991.

MAYBURY-LEWIS, David. Prefácio. In: SANTOS, Silvio Coelho (Org.). O indio perante o direito. Florianópolis: Ed. UFSC, 1982. p. 9-13.

MOTA, Lúcio Tadeu. Etno-história: uma metodologia para abordagem transdisciplinar da história de povos indígenas. Patrimônio e Memória (UNESP), São Paulo, v. 10, p. 5-16, 2014.

SANTOS, Silvio Coelho. Apresentação. In: SANTOS, Silvio Coelho (Org.). Sociedades indigenas e o direito: uma questão de direitos humanos. Florianópolis: Ed. UFSC, 1982. p. 11-16. 